\title{
Exenatide once-weekly injection for the treatment of type 2 diabetes in Chinese patients: current perspectives
}

This article was published in the following Dove Press journal:

Therapeutics and Clinical Risk Management

10 August 2015

Number of times this article has been viewed

\author{
Wuquan Dengl,* \\ Sheng Qiul,* \\ Gangyi Yang ${ }^{2}$ \\ Bing Chen' \\ 'Department of Endocrinology, \\ Southwest Hospital, Third Military \\ Medical University, ${ }^{2}$ Department \\ of Endocrinology, Second Affiliated \\ Hospital, Chongqing Medical \\ University, Chongqing, People's \\ Republic of China \\ *These authors contributed equally \\ to this work
}

\begin{abstract}
Glucagon-like peptide-1 (GLP-1) analogs, such as exenatide, have played an important role as antidiabetic medications in the treatment of type 2 diabetes (T2DM). Like most other hypoglycemic agents, exenatide has a number of actions, including lowering blood glucose, promoting weight loss, improving insulin resistance, and protecting islet $\beta$-cells. Although GLP-1 analogs, combined with other antidiabetic medications, have excellent performance in T2DM, some side effects and imperfections limit its use in clinical practice. Since 2012, a new generation GLP-1 agent, exenatide once weekly (QW), has been available for patients with T2DM in the USA, but not as yet in the People's Republic of China. Previous data indicate that exenatide QW achieves better fasting glucose reductions than sitagliptin or exenatide twice daily, whilst appearing non-inferior to pioglitazone and achieving less reductions than insulin glargine. Exenatide QW was better at improving average postprandial glucose than sitagliptin or titrated insulin glargine, but was inferior to exenatide twice daily. Additionally exenatide QW has a better effect in terms of weight loss than other glycemic medications. Exenatide QW can also reduce blood lipids and lower blood pressure. Accordingly, exenatide QW is cost-effective, achieves good clinical outcomes, and has acceptable side effects, indicating that it has promising prospects for future use in the People's Republic of China.
\end{abstract}

Keywords: diabetes, glycemic control, exenatide once weekly

\section{Introduction}

Diabetes is one of the most common chronic noninfectious diseases worldwide, including in the People's Republic of China. According to the China National Diabetes and Metabolic Disorder Study, the age-standardized prevalence of diabetes in people over 20 years of age was $9.7 \%$ along with $15.5 \%$ for prediabetes in $2008 .{ }^{1}$ The most recent survey, based on the 2010 guideline of the American Diabetes Association, which integrated glycated hemoglobin (HbA1c) into the diagnostic criteria, estimated that the prevalence of diabetes and prediabetes was $11.6 \%-50.1 \%$, respectively, in the People's Republic of China. This suggests that 113.9 million Chinese adults had diabetes and that 493.4 million had prediabetes in $2010 .^{2}$ However, various sampling, study, and analysis methods have yielded different data and results. Nonetheless, all of these findings reflect the serious public concern about diabetes in the People's Republic of China.

A variety of antidiabetic medications has been used for the treatment of diabetes in the last few decades; however, the success rate of blood glucose control remains inadequate. In one report, only $25.8 \%$ of patients with diabetes received antidiabetic treatment and only $39.7 \%$ of those treated had adequate glycemic control $(\mathrm{HbA} 1 \mathrm{c}<7.0 \%){ }^{2}$ The results of other studies revealed that $64 \%$ of patients still fail to achieve adequate glycemic 
control and die prematurely of a variety of complications. ${ }^{3,4}$ In addition to clinical efficacy, the side effects of traditional medicines also impose restrictions on selection of drugs. For example, sulfonylureas, which were the first therapies targeted to insufficient insulin secretion, can cause hypoglycemia. These compounds promote insulin secretion independent of blood glucose levels. In addition, as diabetes progresses, the ability of sulfonylureas to stimulate insulin secretion may decrease. ${ }^{5}$ Similarly, pioglitazone may cause bladder cancer and rosiglitazone, (which can no longer be used in the USA) may cause or worsen congestive heart failure. ${ }^{6}$ In addition, patient compliance with antidiabetic medication is thought to be important when evaluating a medication. These factors may include the complexity of treatment, duration of treatment, route of administration, frequency of dosing, and even cost considerations. ${ }^{4}$ For these reasons, there is a need to develop new drugs to treat type 2 diabetes (T2DM).

Fortunately, a number of new drugs have been developed in recent years. Some of the most popular hypoglycemic drugs include the glucagon-like peptide-1 (GLP-1) analogs and dipeptidyl peptidase (DPP)-4 inhibitors, which have already been shown to have good antidiabetic effects. However, some disadvantages are still inevitable. Exenatide is one of the GLP-1 analogs that has been used as an antidiabetic medication, and has been available since 2005 . In order to improve and refine the quality of hypoglycemic drugs, one of the new generation long-term GLP-1 analogs, exenatide once weekly $(\mathrm{QW})$ injection was approved by the US Food and Drug Administration in 2012. This has helped to alleviate some anti-diabetes drug shortages, but because it has been used in clinical practice for only a short time, its safety and efficacy needs further investigation. In this review, we summarize the previous findings regarding GLP-1 analogs and discuss the prospective clinical application of exenatide QW in the People's Republic of China.

\section{GLP-I, GLP-I analogs, and other antidiabetic agents Overview of GLP-I and GLP-I analogs}

In the early 20 th century, researchers found that some hormones released from the intestine could stimulate insulin secretion after food intake, with an apparent glucose-lowering effect. Subsequently, McIntyre et al and Elrick et al discovered that the insulin secretion was much higher when glucose was taken orally rather than by intravenous injection. ${ }^{7,8}$ This additional activity was termed the "incretin effect" and was thought to account for over $50 \%$ of total insulin secretion after a meal. ${ }^{9}$ In 1987 , by cloning and sequencing of proglucagon genes, Drucker et al and Orskov et al identified the incretin now known as GLP-1 which could promote release of the pancreatic hormone insulin. ${ }^{10,11}$ Under the stimulus of food, GLP-1 could be secreted into the circulation by L-cells in the ileum and colon, inhibiting apoptosis of $\beta$-cells and improving $\beta$-cell function. ${ }^{12}$ However, this endogenous form of GLP-1 was rapidly degraded by DPP-4 and needed to be given by continuous intravenous drip or subcutaneous injection, so its clinical application is limited. ${ }^{13,14}$

In recent years, GLP-1 analogs have come onto the market; these agents not only retain the advantages of GLP-1, but also protect against degradation by DPP-4. In 2005, the first GLP-1 analog, exenatide, was approved by the US Food and Drug Administration for clinical application. This GLP-1 analog was used for T2DM and obtained widespread acceptance by the medical profession after 5 years of clinical use in the People's Republic of China. ${ }^{15}$

\section{Basic research}

Numerous data from experiments conducted in vivo and vitro have been collected to support many new therapeutic measures for controlling T2DM. Research in a mouse model demonstrated that GLP-1 can increase $\beta$-cell proliferation and reduce glucagon secretion from pancreatic $\alpha$-cells. ${ }^{16,17}$ Similar results were observed in obese diabetic $(\mathrm{db} / \mathrm{db})$ mice that underwent prolonged administration of GLP-1, ie, improved blood glycemic excursions and more islet mass and $\beta$-cell neogenesis. ${ }^{18}$

GLP-1 also regulates a wide scope of extrapancreatic effects, including in the digestive system, ocomotor system, and even the central nervous system. GLP-1 can inhibit gastric emptying and small intestinal transit by decreasing gastric smooth muscle motility. ${ }^{19,20}$ GLP-1 also appears to upregulate insulin sensitivity and glucose uptake in adipose tissue and skeletal muscle. ${ }^{21,22}$ Interestingly, rats injected with GLP-1 experienced satiety, which caused reduced caloric intake, indicating that GLP-1 was a physiological mediator of satiety. ${ }^{23,24}$ Meanwhile, some side effects, including increased heart rate and blood pressure, were also observed in rats treated with GLP-1. ${ }^{25}$

As mentioned earlier, unlike GLP-1, GLP-1 analogs can maintain biological activity and are resistant to degradation by DPP-4 through proteolytic cleavage, which are used more often in diabetes therapy. Further, GLP-1 agonists such as exenatide enhanced postprandial insulin secretion, and as well as promoting weight loss and having a hypoglycemic effect. ${ }^{26}$ The properties of GLP-1 described earlier, including glucose-dependent insulin secretion, $\beta$-cell mass expansion, 
coupled with inhibition of glucagon secretion and gastric emptying. This suggests that it would greatly complement current $\beta$-cell therapies.

\section{Clinical study of antidiabetic agents}

Diabetes treatment guidelines from the American Diabetes Association and European Association for the Study of Diabetes have recommended several antihyperglycemic strategies and a number of antidiabetic medications, according to evidence-based medicine. Metformin has regained an approval on the basis of the United Kingdom Prospective Diabetes Study and has been considered the first-line treatment for T2DM since 1998. ${ }^{27}$ Like metformin, GLP-1 can inhibit hepatic gluconeogenesis, and decrease fasting and postprandial blood glucose. ${ }^{28}$ Additionally, GLP-1 also enhances insulin sensitivity and decreases peripheral insulin resistance. ${ }^{29,30}$ Both metformin and GLP-1 were shown to reduce cardiovascular morbidity and mortality, consequently extending the lifespan of T2DM patients. ${ }^{31-33}$ Other hypoglycemic agents like thiazolidinediones also increase insulin sensitivity in the liver and skeletal muscle and inhibit hepatic gluconeogenesis. However, thiazolidinediones can increase appetite and adipogenesis, which eventually leads to weight gain. Further, in contrast with the cardioprotection afforded by metformin and GLP-1, thiazolidinediones frequently induce or aggravate heart failure. ${ }^{34,35}$ Sulfonylureas can stimulate insulin secretion from $\beta$-cells, and have been used since the $1950 \mathrm{~s} .{ }^{36}$ Sulfonylureas are also somewhat efficient in improving insulin levels and reducing blood glucose concentrations. Unfortunately, some studies have shown that this class of drugs results in weight gain and hypoglycemia, accelerates $\beta$-cell apoptosis, and impairs endothelial function. ${ }^{36-39}$ These disadvantages were not found with GLP-1. ${ }^{22,29}$ In recent years, DPP-4 inhibitors have been approved as a new class of antidiabetic drugs because they can inhibit the enzyme which inactivates GLP-1. This increases the effects of endogenous GLP-1, and in turn, enhances glucose-dependent insulin in order to suppress inappropriately elevated glucagon secretion as well as preserve pancreatic $\beta$-cells. ${ }^{40-42}$ However, head-to-head trials have demonstrated that DPP-4 inhibitors have an inferior glucose-lowering effect when compared with GLP-1. ${ }^{43,44}$ Moreover, DPP-4 inhibitors do not appear to have an effect on gastric emptying or weight loss, which limits their clinical application. ${ }^{16,45,46}$

\section{Side effects and disadvantages of exenatide}

While GLP-1 has multiple advantages in the treatment of T2DM, some adverse effects are still unavoidable. The main adverse reactions are gastrointestinal, including nausea, vomiting and diarrhea, however, all of them are relative to moderate. ${ }^{47,48}$ These side effects are mainly seen in the early treatment period. ${ }^{49}$ Other adverse events, such as injection site reactions and hypoglycemia, are rare, but the risk of hypoglycemia may increase when exenatide is used in combination with a sulfonylurea. ${ }^{50}$ Based on post-marketing data and several clinical studies, exenatide has been associated with both fatal and non-fatal hemorrhagic or necrotizing pancreatitis. ${ }^{51}$ It is still controversial whether there is an increased risk of pancreatic cancer with GLP-1 analogs when compared with other antidiabetic therapies. ${ }^{52}$ It has been reported that GLP-1 may cause thyroid C-cell adenomas in rodents. ${ }^{53}$ In contrast, there are some research data indicating that the risk of developing medullary thyroid cancer is very low in patients receiving GLP-1 therapy. ${ }^{54}$ The calcitonin was maintained at low levels and no evidence of C-cell activation was found. However, the exact relationship between GLP-1-based therapies and the risk of pancreatic or thyroid cancer remains to be clarified. ${ }^{55}$

As mentioned earlier, GLP-1 is easily inactivated by DPP-4, which greatly limits its clinical application. ${ }^{56}$ To avoid this problem, researchers developed GLP-1 receptor agonists, including a subcutaneous injectable formulation of exenatide, which only has a short plasma half-life of 2-4 hours and a duration of action of approximately 8 hours. Inevitably, fluctuating plasma concentrations of the drug may easily aggravate adverse effects such as diarrhea, indigestion, and nausea. The daily injection also causes pain and is inconvenient. ${ }^{57}$ In recent years, researchers have developed exenatide QW to improve drug efficacy, safety, and patient compliance. Its superiority has been established by a series of head-to-head clinical trials. ${ }^{58-60}$

\section{Exenatide once weekly Pharmacology and pharmacodynamics}

Exenatide QW is an agent combining exenatide within a microspheric technology that contains poly (lactic-co-glycolic acid), which can encase the drug molecule and enable natural hydrolysis of the ester linkages. The drug molecule is released continuously into the circulation during microspheric degradation by non-enzymatic hydrolysis under the skin, ${ }^{61,62}$ allowing exenatide QW to have a much longer half-life than exenatide twice daily. Moreover, previous experiments established that a single subcutaneous dose of exenatide QW could lead to a dose-related increase in concentrations of exenatide in plasma, subsequently achieving a multiple-peak profile over approximately 10 weeks. ${ }^{63}$ Both exenatide QW $0.8 \mathrm{mg}$ and exenatide 
QW 2.0 mg can achieve effective therapeutic plasma concentrations $(>50 \mathrm{pg} / \mathrm{mL})$. However, patients dosed with $2 \mathrm{mg}$ of exenatide QW can achieve both fasting plasma and postprandial glucose control, while the group dosed with $0.8 \mathrm{mg}$ showed only improved fasting plasma glucose control. This indicates that $2.0 \mathrm{mg}$ may be the optimal dose of exenatide $\mathrm{QW} .{ }^{63}$ Therapeutic doses and steady-state plasma concentrations of exenatide QW were achieved after approximately 2 weeks and 6-7 weeks, respectively. After discontinuation of therapy, it took 10 weeks to reduce GLP-1 analogs to a minimally detectable plasma concentration of $10 \mathrm{pg} / \mathrm{mL} .{ }^{63}$ As exenatide $\mathrm{QW}$ is eliminated by glomerular filtration, it cannot be used in patients whose creatinine clearance is less than $30 \mathrm{~mL}$ per minute or in patients with end-stage renal disease.

\section{Clinical effect of exenatide QW}

As with most other antidiabetic drugs used in the treatment of T2DM, a series of duration studies have revealed the safety and efficacy of exenatide QW. In general, exenatide QW achieves significantly greater reductions in $\mathrm{HbA1c}$ when compared with exenatide twice daily, titrated insulin glargine, sitagliptin and pioglitazone on the metformin background. ${ }^{32,49,59,64,68}$ Overall, there were more patients using exenatide QW to achieve the composite than using other hypoglycemic drugs. Notably, patients who switched from daily sitagliptin or pioglitazone to exenatide QW achieved improved or sustained glycemic control. ${ }^{64}$ Regarding patients fasting glucose, treated with exenatide QW it had apparently more reductions than sitagliptin and exenatide twice daily, ${ }^{64,66,69}$ while appearing non-inferior to pioglitazone and with less reductions than insulin glargine. ${ }^{49,64}$ According to self-monitored blood glucose tests, exenatide QW improved average postprandial glucose to a greater extent than sitagliptin and titrated insulin glargine; however, exenatide QW is inferior to exenatide twice daily in improving average postprandial glucose (Table 1). ${ }^{49,64,66}$ The exenatide QW group achieved more weight loss (range $2-4 \mathrm{~kg}$ ) than the sitagliptin group and similar with exenatide twice daily group, while the groups receiving pioglitazone and glargine showed weight gains up to 4-5 kg (Table 1)..$^{32,49,64-66,70,71}$ Reductions in weight and $\mathrm{HbA} 1 \mathrm{c}$ were seen in $70 \%-79 \%$ of patients on exenatide QW. Although the $\mathrm{HbAlc}$ reduction was only significantly greater than $51 \%-74 \%$ of exenatide twice daily diabetics, $46 \%$ of sitagliptin diabetics, $14 \%$ of pioglitazone diabetics, and $31 \%$ of insulin glargine diabetics, the improvement in glycemic parameters was assumed to be independent of weight loss..$^{32,49,64,66}$ Meanwhile, the study investigated other systemic effects in patients treated with exenatide QW, including mean systolic blood pressure, which decreased by 3-5 mmHg. In patients treated with exenatide QW, mean total cholesterol and low-density lipoprotein cholesterol levels were significantly improved, but there was no significant effect on high-density lipoprotein cholesterol. In contrast, the improvement in total cholesterol was less for exenatide twice daily, compared with exenatide WQ (Table 2). However, no meaningful differences in fasting lipids were found between patients treated with exenatide QW, those treated with sitagliptin, and those treated with insulin glargine. ${ }^{32,49,64,66,67}$ The insulin-to-glucose ratio after 14 weeks of treatment indicated that patients on exenatide QW had a significant increase in $\beta$-cell sensitivity. ${ }^{71}$ Moreover, B-type natriuretic peptide was reduced on sitagliptin, pioglitazone, and exenatide QW therapy. However, exenatide QW was the only therapy which caused a significant reduction in the albumin-to-creatinine ratio. ${ }^{64}$ Exenatide QW was non-inferior to metformin in the Duration-4 study. ${ }^{32}$ The combination of exenatide QW with other antidiabetic medications appeared to be well tolerated in some studies. In a recent study, Japanese T2DM patients treated with exenatide QW and oral antidiabetic medications showed great weight loss and glycemic control through 52 weeks, indicating that exenatide QW can be used as an adjunctive treatment for T2DM in this patient population. ${ }^{72}$ A head-to-head trial comparing exenatide QW with liraglutide suggested that both exenatide QW and liraglutide improved glycemic control as well as weight loss. Interestingly, in one study, better improvement of HbA1c and weight loss were achieved in the liraglutide group when compared with the exenatide group..$^{73}$ In other studies, opposite results were found. ${ }^{49,64-67,70,74-77}$ The reasons for these unexpected differences are presently unknown. No major hypoglycemic events were reported and gastrointestinal side effects were mild in all treatment groups. ${ }^{32,49,64-66,68,74-76}$ However, withdrawals due to gastrointestinal adverse events were more frequent with liraglutide. ${ }^{73}$

\section{Side effects and safety of exenatide QW}

Recent studies reported that $26.4 \%$ of patients had nausea, which was the most common adverse event in all the headto-head trials. Other gastrointestinal side effects, such as vomiting and diarrhea, were typically less frequent than nausea. ${ }^{49,64,66,67,78,79}$ In most patients, these adverse reactions resolved by 3-4 weeks, whilst a small proportion of patients showed intermittent side effects, which peaked by 6-8 weeks of therapy, at which time drug levels approached steady state. ${ }^{80}$ In general, there were fewer gastrointestinal adverse effects in patients treated with exenatide QW than 


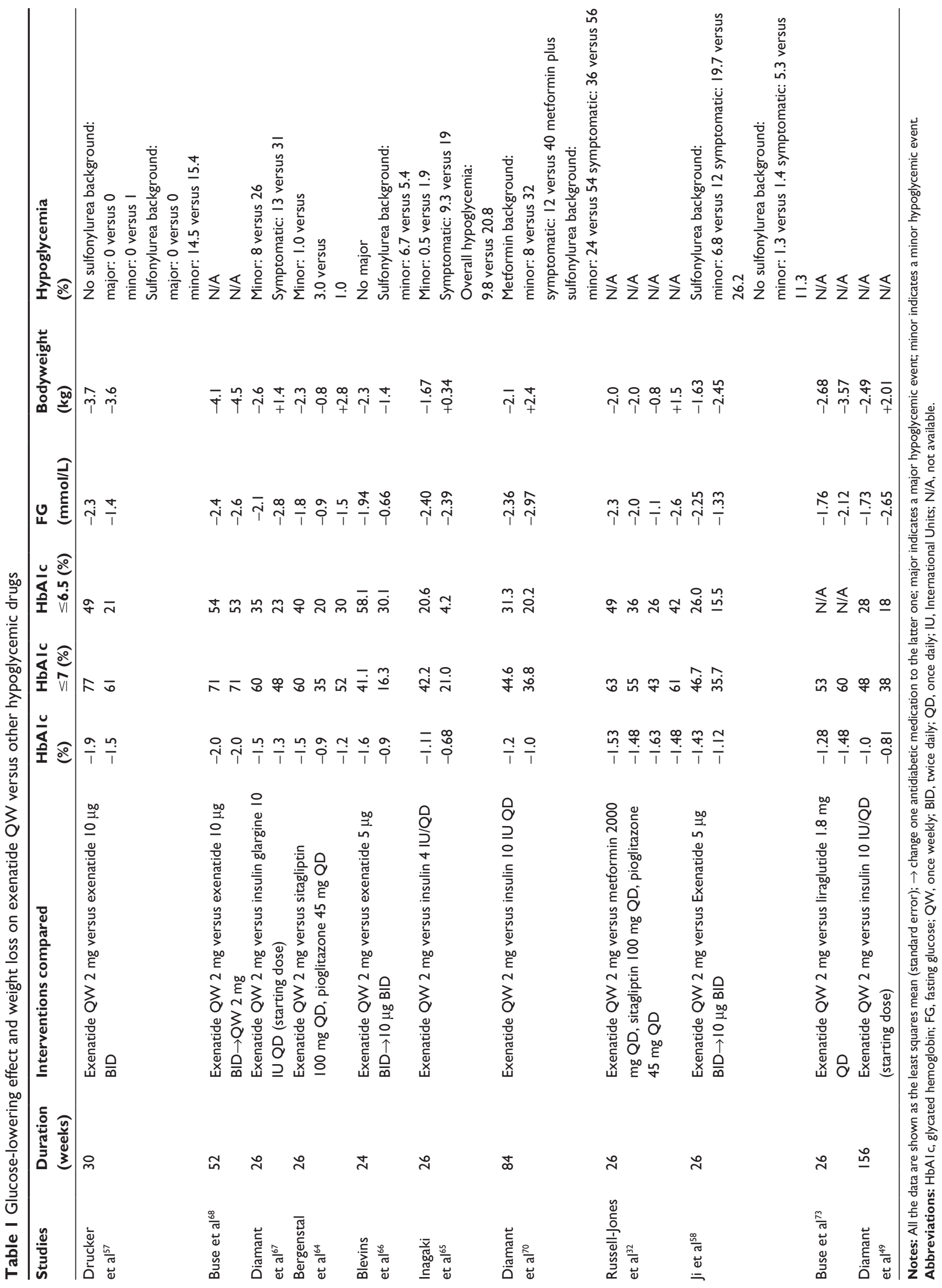


Table 2 Effect of exenatide QW on blood lipids and blood pressure versus effects of other hypoglycemic drugs

\begin{tabular}{|c|c|c|c|c|c|c|c|c|}
\hline References & $\begin{array}{l}\text { Duration } \\
\text { (weeks) }\end{array}$ & $\begin{array}{l}\text { Interventions } \\
\text { compared }\end{array}$ & $\begin{array}{l}\text { TC } \\
(\mathrm{mmol} / \mathrm{L})\end{array}$ & $\begin{array}{l}\text { HDL-C } \\
(\mathrm{mmol} / \mathrm{L})\end{array}$ & $\begin{array}{l}\text { LDL-C } \\
(\mathrm{mmol} / \mathrm{L})\end{array}$ & $\begin{array}{l}\text { TG } \\
(\mathrm{mmol} / \mathrm{L})\end{array}$ & $\begin{array}{l}\text { SBP } \\
(\mathrm{mmHg})\end{array}$ & $\begin{array}{l}\text { DBP } \\
(\mathrm{mmHg})\end{array}$ \\
\hline \multirow[t]{2}{*}{ Drucker et $\mathrm{al}^{57}$} & 30 & Exenatide QW 2 mg versus & -0.31 & -0.02 & -0.13 & -0.03 & -4.7 & -1.7 \\
\hline & & exenatide $10 \mu \mathrm{g}$ BID & -0.10 & -0.03 & +0.03 & -0.03 & -3.4 & -1.7 \\
\hline \multirow[t]{2}{*}{ Diamant et $\mathrm{al}^{67}$} & 26 & Exenatide QW 2 mg versus & -0.12 & 0.00 & -0.05 & $\mathrm{~N} / \mathrm{A}$ & -3 & -1 \\
\hline & & $\begin{array}{l}\text { insulin glargine I0 IU QD } \\
\text { (starting dose) }\end{array}$ & -0.04 & 0.01 & +0.04 & $\mathrm{~N} / \mathrm{A}$ & -1 & -1 \\
\hline \multirow[t]{2}{*}{ Buse et $\mathrm{a}^{68}$} & 52 & Exenatide QW 2 mg versus & -0.25 & -0.02 & -0.09 & -0.27 & -6.2 & -2.8 \\
\hline & & $\begin{array}{l}\text { exenatide } 10 \mu \mathrm{g} \text { BID } \rightarrow Q W \\
2 \mathrm{mg}\end{array}$ & -0.23 & -0.04 & -0.07 & -0.22 & -3.8 & -1.8 \\
\hline \multirow[t]{3}{*}{ Bergenstal et a ${ }^{64}$} & 26 & Exenatide QW $2 \mathrm{mg}$ versus & -0.02 & +0.05 & -0.03 & -0.10 & -3.75 & No \\
\hline & & sitagliptin 100 mg QD, & +0.07 & +0.05 & +0.04 & -0.10 & +0.15 & difference \\
\hline & & pioglitazone 45 mg QD & +0.16 & +0.15 & +0.04 & -0.35 & -1.25 & \\
\hline \multirow[t]{2}{*}{ Blevins et $\mathrm{al}^{66}$} & 24 & Exenatide QW $2 \mathrm{mg}$ versus & -0.40 & 0.00 & -0.17 & +0.94 & -1.2 & +0.2 \\
\hline & & $\begin{array}{l}\text { exenatide } 5 \mu \mathrm{g} \text { BID } \rightarrow 10 \mu \mathrm{g} \\
\text { BID }\end{array}$ & +0.02 & +0.03 & +0.07 & +0.99 & -2.9 & -0.1 \\
\hline \multirow[t]{2}{*}{ Inagaki et al ${ }^{65}$} & 26 & Exenatide QW $2 \mathrm{mg}$ versus & -1.67 & -0.52 & -1.41 & 1.02 & $\mathrm{~N} / \mathrm{A}$ & $\mathrm{N} / \mathrm{A}$ \\
\hline & & insulin 4 IU QD & -1.67 & $-0.5 \mathrm{I}$ & -1.42 & 1.02 & $\mathrm{~N} / \mathrm{A}$ & $\mathrm{N} / \mathrm{A}$ \\
\hline \multirow[t]{3}{*}{ Ji et $a^{58}$} & 26 & Exenatide QW 2 mg versus & -0.24 & -0.003 & -0.19 & +0.01 & -5.41 & -1.62 \\
\hline & & exenatide $5 \mu \mathrm{g}$ & -0.21 & -0.012 & -0.21 & +0.01 & -5.38 & -2.26 \\
\hline & & $\mathrm{BID} \rightarrow \mathrm{I0} \mu \mathrm{g} \mathrm{BID}$ & & & & & & \\
\hline \multirow{2}{*}{ Buse et $\mathrm{al}^{73}$} & 26 & Exenatide QW 2 mg versus & -0.06 & +0.02 & -0.05 & $\mathrm{~N} / \mathrm{A}$ & -2.48 & -0.49 \\
\hline & & liraglutide $1.8 \mathrm{mg}$ QD & -0.15 & +0.02 & -0.09 & N/A & -3.45 & -0.51 \\
\hline \multirow[t]{2}{*}{ Diamant et $\mathrm{al}^{49}$} & 156 & Exenatide QW 2 mg versus & -0.13 & +0.05 & -0.17 & +1.02 & -2 & -2 \\
\hline & & $\begin{array}{l}\text { insulin I0 IU QD (starting } \\
\text { dose) }\end{array}$ & -0.01 & +0.05 & -0.13 & +0.97 & +2 & -2 \\
\hline
\end{tabular}

Notes: All the data are shown as the least squares mean (standard error).

Abbreviations: TC, total cholesterol; HDL-C, high-density lipoprotein-cholesterol; LDL-C, low-density lipoprotein-cholesterol; TG, triglycerides; SBP, systolic blood pressure; DBP, diastolic blood pressure; QW, once weekly; BID, twice daily; QD, once daily; IU, International Units; N/A, not available.

in those treated with exenatide twice daily, and less than $2 \%$ of patients stopped treatment because of gastrointestinal side effects. However, injection site reactions, including pain, erythema, bruising, hemorrhage, induration, and skin nodules, appeared to be more common in patients treated with exenatide QW. Fortunately, the incidence of injection site reactions decreased over time. ${ }^{66,71}$ As with the traditional GLP-1 analogs, the prevalence of hypoglycemia in patients treated with exenatide QW was quite low in all the studies, unless exenatide QW was used with sulfonylureas. Additionally, the action of GLP-1 agonists potentiated glucose-dependent insulin secretion, which resulted in a low incidence of hypoglycemia (Table 1). ${ }^{32,64,66,79,80}$ Although some studies showed that exenatide QW was associated with an increased prevalence of thyroid C-cell tumors in rats and in female mice, no similar results have been reported in humans. As mentioned previously, pancreatitis and/or pancreatic cancer were found in a few patients in some of the clinical trials or in the post-marketing data; ${ }^{66,67}$ however, whether these events were caused by exenatide QW directly or whether other factors were involved is still not known. ${ }^{81}$ In the renal system, direct nephrotoxicity has not been observed with exenatide QW in the preclinical and clinical studies; however, it did appear to affect renal function by increasing serum creatinine, renal impairment, worsened chronic renal failure and acute renal failure, which could be reversed in most cases by renal protection measures, discontinuation of exenatide, or discontinuation of other potentially causative agents. ${ }^{79}$

\section{Cost utility of exenatide QW}

There have been several cost-effectiveness evaluations done in a cohort of patients treated with exenatide QW or other hypoglycemic drugs. The computer simulation model most commonly used to project lifetime clinical outcomes and complication costs is the IMS CORE Diabetes Model (IMS CDM). One typical study compared exenatide QW with sitagliptin or pioglitazone for over 35 years with IMS CDM. Exenatide QW showed significant superiority in several ways. For example, exenatide QW increased both life expectancy and quality-adjusted life years (QALYs) by 0.28 years more than sitagliptin. Compared with pioglitazone, life expectancy and QALYs also increased by 0.17 and 0.24 years, respectively. Further, compared with sitagliptin or pioglitazone, exenatide QW was shown to save US \$2215 and US \$933, respectively, in direct costs per patient as a result of decreasing the lifetime costs of complications caused by cardiovascular disease and neuropathy. Overall, compared with sitagliptin or 
pioglitazone, exenatide QW was projected to reduce the costs of diabetes-related complications over a patient's lifetime. ${ }^{82}$

In the UK and USA, the IMS CDM was also used to project clinical and economic outcomes for T2DM patients treated with exenatide QW or insulin glargine. A study creatively set exenatide $\mathrm{QW}$ at a price equivalent to liraglutide $1.2 \mathrm{mg}$, and exenatide QW was shown to be more effective, although more costly than insulin glargine. The cost effectiveness, in practice, will depend on the price of exenatide QW on the market and should be verified by long-term use in the future ${ }^{84}$ To analyze the long-term cost-utility of exenatide QW versus insulin glargine, a similar comparison with a computer simulation model was done in the USA in 2012. Based on data from the Duration-3 study, exenatide QW was associated with an incremental cost of $\$ 3,914$, but life expectancy was increased by 0.135 years, along with qualityadjusted life expectancy, which increased by 0.246 years. Researchers assumed that patients would pay a threshold of $\$ 50,000 / \mathrm{QALY}$, and that the incremental cost-effectiveness ratio would be $\$ 15,936 / \mathrm{QALY}$. This study concluded that exenatide QW was more cost-effective than insulin glargine. ${ }^{84}$ Another important model, known as the Archimedes model, was used to assess health and economic outcomes for exenatide QW, pioglitazone, and insulin therapies in $~ 25,000$ virtual patients with T2DM over 20 years. Assuming moderate adherence, exenatide QW increased QALYs by $\sim 0.3$ per person and costs per life-year by $\$ 469$. Meanwhile, pioglitazone or high-adherence insulin did not change QALYs, but increased the cost per life-year by $\$ 69$ and $\$ 87$, respectively. ${ }^{85}$ US researchers have recently developed a decision model to evaluate the short-term cost-effectiveness of once-daily liraglutide and exenatide QW for the treatment of T2DM. The results indicated that it was the "chosen clinical data" that determined the cost-effectiveness of liraglutide $1.8 \mathrm{mg}$ once daily versus $2 \mathrm{mg}$ exenatide $\mathrm{QW}{ }^{86}$

\section{Current perspectives in the People's Republic of China}

Until now, exenatide QW has not been approved by the People's Republic of China Food and Drug Administration. There have been a few clinical trials investigating the curative effect and side effects of exenatide QW in Chinese subjects. Cui et al treated 25 Chinese T2DM patients with single doses and multiple doses of exenatide QW to evaluate its pharmacokinetics, safety, and tolerability. ${ }^{15}$ These patients were treated with diet modification, exercise alone or in combination with stable metformin doses, and received weekly doses of $2 \mathrm{mg}$ exenatide QW for 10 weeks. All 25 patients attained steady-state plasma exenatide concentrations (average $299 \mathrm{pg} / \mathrm{mL}$ ) within 8 weeks, and indices such as fasting plasma glucose $(\sim 3.0 \mathrm{mmol} / \mathrm{L}), \mathrm{HbAlc}$ $(\sim 1.0 \%)$, and body weight $(\sim 3.8 \mathrm{~kg})$ were decreased from baseline to 10 weeks. Compared with patients in other Asian countries, Chinese patients have similar ethnic and racial backgrounds and diet habits, and have been found to have similar pharmacokinetic profiles. ${ }^{58,72}$ In terms of safety and tolerability, exenatide QW showed little risk of causing hypoglycemia and the most frequently reported side effects were diarrhea and vomiting, which were mild and well tolerated.

T2DM patients are rapidly increasing in number year by year in the People's Republic of China because of the huge population base and the high incidence rate of diabetes. With improved living standards and the lifestyle changes, there has been a shift from undernutrition to overnutrition, resulting in an increasing epidemic of obesity in the People's Republic of China. Moreover, Chinese T2DM patients have fewer numbers and poorer function of islet $\beta$-cells compared with diabetics in western countries. This leads to obese Chinese patients having a poorer regulation ability of islet $\beta$-cells. As mentioned earlier, exenatide $\mathrm{QW}$ can enhance the function of $\beta$-cells in many ways, such as increasing their quantity, preventing their apoptosis, and improving their sensitivity, which leads to better blood glucose control. ${ }^{16,17}$ Additionally, patients treated with exenatide QW can lose significant amounts of weight, thus effectively reducing the risk of cardiovascular complications associated with diabetes-related high blood pressure and blood lipids. ${ }^{87}$ Major gastrointestinal adverse reactions, including nausea, vomiting, and diarrhea, which occur predominantly during the first 6-8 weeks of therapy, are gradually reduced. ${ }^{32,49,64,66-68,73,79,80}$

Although it has excellent safety and tolerability, exenatide QW is quite expensive, which may limit its application in less developed countries. Many studies, as mentioned previously, have confirmed that exenatide QW has therapeutic effects in common with most hypoglycemic drugs, and even better than other antidiabetic agents in some aspects. Computer simulation economic models show that exenatide QW has good costeffectiveness and clinical outcomes. All in all, exenatide QW will fulfill the need for another treatment option in diabetic patients with suboptimal glycemic control and could have a promising future in the People's Republic of China.

\section{Disclosure}

The authors report no conflicts of interest in this work.

\section{References}

1. Yang W, Zhu D, Ge J, et al. Prevalence of diabetes among men and women in China. N Engl J Med. 2008;362(12):1090-1101.

2. Xu Y, Wang L, He J, et al. Prevalence and control of diabetes in Chinese adults. JAMA. 2013;310(9):948-959. 
3. Bailey CJ, Kodack M. Patient adherence to medication requirements for therapy of type 2 diabetes. Int J Clin Pract. 2011;65(3):314-322.

4. Miller BR, Nguyen H, Hu CJ, Lin C, Nguyen QT. New and emerging drugs and targets for type 2 diabetes: reviewing the evidence. Am Health Drug Benefits. 2014;7(8):452-463.

5. Raptis SA, Dimitriadis GD. Oral hypoglycemic agents: insulin secretagogues, alpha-glucosidase inhibitors and insulin sensitizers. Exp Clin Endocrinol Diabetes. 2001;109 Suppl 2:S265-S287.

6. Lebovitz HE. Differentiating members of the thiazolidinedione class: a focus on safety. Diabetes Metab Res Rev. 2002;18(S2):S23-S29.

7. Mcintyre N, Holdsworth CD, Turner DS. New interpretation of oral glucose tolerance. Lancet. 1964;2(7349):20-21.

8. Elrick H, Stimmler L, Hlad CJ Jr, Arai Y. Plasma insulin response to oral and intravenous glucose administration. J Clin Endocrinol Metab. 1964;24:1076-1082.

9. Perley MJ, Kipnis DM. Plasma insulin responses to oral and intravenous glucose: studies in normal and diabetic subjects. J Clin Invest. 1967;46(12):1954-1962.

10. Drucker DJ, Philippe J, Jepeal L, Habener JF. Glucagon gene 5 '-flanking sequences promote islet cell-specific gene transcription. J Biol Chem. 1987;262(32):15659-15665.

11. Orskov C, Holst JJ, Poulsen SS, Kirkegaard P. Pancreatic and intestinal processing of proglucagon in man. Diabetologia. 1987;30(11): 874-881.

12. Nauck MA, Kleine N, Orskov C, Holst JJ, Willms B, Creutzfeldt W. Normalization of fasting hyperglycaemia by exogenous glucagon-like peptide 1 (7-36 amide) in type 2 (non-insulin-dependent) diabetic patients. Diabetologia. 1993;36(8):741-744.

13. Deacon CF, Pridal L, Klarskov L, Olesen M, Holst JJ. Glucagon-like peptide 1 undergoes differential tissue-specific metabolism in the anesthetized pig. Am J Physiol. 1996;271(3 Pt 1):E458-E464.

14. Hansen L, Deacon CF, Orskov C, Holst JJ. Glucagon-like peptide-1(7-36)amide is transformed to glucagon-like peptide-1-(9-36)amide by dipeptidyl peptidase IV in the capillaries supplying the L cells of the porcine intestine. Endocrinology. 1999;140(11):5356-5363.

15. Cui YM, Guo XH, Zhang DM, et al. Pharmacokinetics, safety, and tolerability of single- and multiple-dose exenatide once weekly in Chinese patients with type 2 diabetes mellitus. J Diabetes. 2013;5(2): $127-135$.

16. Drucker DJ, Nauck MA. The incretin system: glucagon-like peptide-1 receptor agonists and dipeptidyl peptidase- 4 inhibitors in type 2 diabetes. Lancet. 2006;368(9548):1696-1705.

17. Edvell A, Lindström P. Initiation of increased pancreatic islet growth in young normoglycemic mice (Umea +/?). Endocrinology. 1999;140(2): 778-783.

18. Stoffers DA, Kieffer TJ, Hussain MA, et al. Insulinotropic glucagonlike peptide 1 agonists stimulate expression of homeodomain protein IDX-1 and increase islet size in mouse pancreas. Diabetes. 2000;49(5): 741-748.

19. Giralt M, Vergara P. Glucagonlike peptide-1 (GLP-1) participation in ileal brake induced by intraluminal peptones in rat. Dig Dis Sci. 1999; 44(2):322-329.

20. Tolessa T, Gutniak M, Holst JJ, Efendic S, Hellstr M PM. Inhibitory effect of glucagon-like peptide- 1 on small bowel motility. Fasting but not fed motility inhibited via nitric oxide independently of insulin and somatostatin. J Clin Invest. 1998;102(4):764-774.

21. Wu H, Sui C, Xu H, et al. The GLP-1 Analogue exenatide improves hepatic and muscle insulin sensitivity in diabetic rats: tracer studies in the basal state and during hyperinsulinemic-euglycemic clamp. J Diabetes Res. 2014;2014:524517.

22. Perfetti R, Merkel P. Glucagon-like peptide-1: a major regulator of pancreatic beta-cell function. Eur J Endocrinol. 2000;143(6):717-725.

23. van Dijk G, Thiele TE. Glucagon-like peptide-1 (7-36) amide: a central regulator of satiety and interoceptive stress. Neuropeptides. 1999; 33(5):406-414.

24. Turton MD, O'Shea D, Gunn I, et al. A role for glucagon-like peptide-1 in the central regulation of feeding. Nature. 1996;379:69-72.
25. Drucker DJ. Minireview: the glucagon-like peptides. Endocrinology. 2001;142(2):521-527.

26. Padrutt I, Lutz TA, Reusch CE, Zini E. Effects of the glucagon-like peptide-1 (GLP-1) analogues exenatide, exenatide extended-release, and of the dipeptidylpeptidase-4 (DPP-4) inhibitor sitagliptin on glucose metabolism in healthy cats. Res Vet Sci. 2015;99:23-29.

27. UK Prospective Diabetes Study (UKPDS) Group. Effect of intensive blood-glucose control with metformin on complications in overweight patients with type 2 diabetes (UKPDS 34). UK Prospective Diabetes Study (UKPDS) Group. Lancet. 1998;352(9131):854-865.

28. Kolterman OG, Buse JB, Fineman MS, et al. Synthetic exendin-4 (exenatide) significantly reduces postprandial and fasting plasma glucose in subjects with type 2 diabetes. J Clin Endocrinol Metab. 2003; 88(7):3082-3089.

29. Zander M, Madsbad S, Madsen JL, Holst JJ. Effect of 6-week course of glucagon-like peptide 1 on glycaemic control, insulin sensitivity, and beta-cell function in type 2 diabetes: a parallel-group study. Lancet. 2002;359(9309):824-830.

30. $\mathrm{Xu} \mathrm{W}, \mathrm{Bi} Y$, Sun Z, et al. Comparison of the effects on glycaemic control and $\beta$-cell function in newly diagnosed type 2 diabetes patients of treatment with exenatide, insulin or pioglitazone: a multicentre randomized parallel-group trial (the CONFIDENCE study). J Intern Med. 2015; 277(1):137-150.

31. Martin-Montalvo A, Mercken EM, Mitchell SJ, et al. Metformin improves healthspan and lifespan in mice. Nat Commun. 2013; 4:2192.

32. Russell-Jones D, Cuddihy RM, Hanefeld M, et al. Efficacy and safety of exenatide once weekly versus metformin, pioglitazone, and sitagliptin used as monotherapy in drug-naive patients with type 2 diabetes (DURATION-4): a 26-week double-blind study. Diabetes Care. 2012; 35(2):252-258.

33. Knowler WC, Barrett-Connor E, Fowler SE, et al. Reduction in the incidence of type 2 diabetes with lifestyle intervention or metformin. N Engl J Med. 2002;346(6):393-403.

34. Ahmadian M, Suh JM, Hah N, et al. PPAR $\gamma$ signaling and metabolism: the good, the bad and the future. Nat Med. 2013;19(5):557-566.

35. Winterstein AG. Rosiglitazone and the risk of adverse cardiovascular outcomes. Clin Pharmacol Ther. 2011;89(6):776-778.

36. UK Prospective Diabetes Study (UKPDS) Group. Intensive bloodglucose control with sulphonylureas or insulin compared with conventional treatment and risk of complications in patients with type 2 diabetes (UKPDS 33). UK Prospective Diabetes Study (UKPDS) Group. Lancet. 1998;352(9131):837-853.

37. Maedler K, Carr RD, Bosco D, Zuellig RA, Berney T, Donath MY. Sulfonylurea induced beta-cell apoptosis in cultured human islets. $J$ Clin Endocrinol Metab. 2005;90(1):501-506.

38. Holstein A, Plaschke A, Egberts E. Lower incidence of severe hypoglycaemia in patients with type 2 diabetes treated with glimepiride versus glibenclamide. Diabetes Metab Res Rev. 2001;17(6):467-473.

39. Gallwitz B, Guzman J, Dotta F, et al. Exenatide twice daily versus glimepiride for prevention of glycaemic deterioration in patients with type 2 diabetes with metformin failure (EUREXA): an open-label, randomised controlled trial. Lancet. 2012;379(9833):2270-2278.

40. Drucker DJ. The biology of incretin hormones. Cell Metab. 2006; 3(3):153-165.

41. Tews D, Werner U, Eckel J. Enhanced protection against cytokineand fatty acid-induced apoptosis in pancreatic beta cells by combined treatment with glucagon-like peptide-1 receptor agonists and insulin analogues. Horm Metab Res. 2008;40(3):172-180.

42. Burcelin R, Gourdy P, Dalle S. GLP-1-based strategies: a physiological analysis of differential mode of action. Physiology (Bethesda). 2014; 29(2):108-121.

43. DeFronzo RA, Okerson T, Viswanathan P, Guan X, Holcombe JH, MacConell L. Effects of exenatide versus sitagliptin on postprandial glucose, insulin and glucagon secretion, gastric emptying, and caloric intake: a randomized, cross-over study. Curr Med Res Opin. 2008; 24(10):2943-2952. 
44. Pratley RE, Nauck M, Bailey T, et al. Liraglutide versus sitagliptin for patients with type 2 diabetes who did not have adequate glycaemic control with metformin: a 26-week, randomised, parallel-group, openlabel trial. Lancet. 2010;375(9724):1447-1456.

45. Ahrén B, Gomis R, Standl E, Mills D, Schweizer A. Twelve- and 52-week efficacy of the dipeptidyl peptidase IV inhibitor LAF237 in metformintreated patients with type 2 diabetes. Diabetes Care. 2004;27(12): 2874-2880.

46. Vella A, Bock G, Giesler PD, et al. Effects of dipeptidyl peptidase-4 inhibition on gastrointestinal function, meal appearance, and glucose metabolism in type 2 diabetes. Diabetes. 2007;56(5):1475-1480.

47. Hansotia T, Drucker DJ. GIP and GLP-1 as incretin hormones: lessons from single and double incretin receptor knockout mice. Regul Peptides. 2005;128(2):125-134.

48. Wang T, Gou Z, Wang F, Ma M, Zhai S. Comparison of GLP-1 analogues versus sitagliptin in the management of type 2 diabetes: systematic review and meta-analysis of head-to-head studies. PLoS One. 2014; 9(8):e103798.

49. Diamant M, Van Gaal L, Guerci B, et al. Exenatide once weekly versus insulin glargine for type 2 diabetes (DURATION-3): 3-year results of an open-label randomised trial. Lancet Diabetes Endocrinol. 2014;2(6): 464-473.

50. George RE, Joseph S. A review of newer treatment approaches for type-2 diabetes: focusing safety and efficacy of incretin based therapy. Saudi Pharm J. 2014;22(5):403-410.

51. Dore DD, Seeger JD, Arnold Chan K. Use of a claims-based active drug safety surveillance system to assess the risk of acute pancreatitis with exenatide or sitagliptin compared to metformin or glyburide. Curr Med Res Opin. 2009;25(4):1019-1027.

52. Elashoff M, Matveyenko AV, Gier B, Elashoff R, Butler PC. Pancreatitis, pancreatic, and thyroid cancer with glucagon-like peptide-1-based therapies. Gastroenterology. 2011;141(1):150-156.

53. Bjerre Knudsen L, Madsen LW, Andersen SR, et al. Glucagon-like peptide-1 receptor agonists activate rodent thyroid C-cells causing calcitonin release and C-cell proliferation. Endocrinology. 2010;151(4): $1473-1486$.

54. Korner M, Stockli M, Waser B, Reubi JC. GLP-1 receptor expression in human tumors and human normal tissues: potential for in vivo targeting. J Nucl Med. 2007;48(5):736-743.

55. Wenten M, Gaebler JA, Hussein M, et al. Relative risk of acute pancreatitis in initiators of exenatide twice daily compared with other anti-diabetic medication: a follow-up study. Diabetic Med. 2012;29(11): 1412-1418.

56. Deacon CF, Johnsen AH, Holst JJ. Peptide-1 yields an N-terminally endogenous. Degradation of glucagon-like peptide-1 by human plasma in vitro yields an N-terminally truncated peptide that is a major endogenous metabolite in vivo. J Clin Endocrinol Metab. 1995;80(3): 952-957.

57. Drucker DJ, Buse JB, Taylor K, et al. Exenatide once weekly versus twice daily for the treatment of type 2 diabetes: a randomised, openlabel, non-inferiority study. Lancet. 2008;372:1240-1250.

58. Ji L, Onishi Y, Ahn CW, et al. Efficacy and safety of exenatide onceweekly versus exenatide twice-daily in Asian patients with type 2 diabetes mellitus. J Diabetes Investig. 2013;4(1):53-61.

59. Stonehouse A, Walsh B, Cuddihy R. Exenatide once-weekly clinical development: safety and efficacy across a range of background therapies. Diabetes Technol Ther. 2011;13(10):1063-1069.

60. Drucker DJ, Buse JB, Taylor K, et al. Exenatide once weekly versus twice daily for the treatment of type 2 diabetes: a randomised, openlabel, non-inferiority study. Lancet. 2008;372(9645):1240-1250.

61. DeYoung MB, MacConell L, Sarin V, Trautmann M, Herbert P. Encapsulation of exenatide in poly-(D,L-lactide-co-glycolide) microspheres produced an investigational long-acting once-weekly formulation for type 2 diabetes. Diabetes Technol Ther. 2011;13(11): $1145-1154$.

62. Cai Y, Wei L, Ma L, et al. Long-acting preparations of exenatide. Drug Des Devel Ther. 2013;7:963-970.
63. Fineman M, Flanagan S, Taylor K, et al. Pharmacokinetics and pharmacodynamics of exenatide extended-release after single and multiple dosing. Clin Pharmacokinet. 2011;50(1):65-74.

64. Bergenstal RM, Wysham C, MacConell L, et al. Efficacy and safety of exenatide once weekly versus sitagliptin or pioglitazone as an adjunct to metformin for treatment of type 2 diabetes (DURATION-2): a randomised trial. Lancet. 2010;376(9739):431-439.

65. Inagaki N, Atsumi Y, Oura T, Saito H, Imaoka T. Efficacy and safety profile of exenatide once weekly compared with insulin once daily in Japanese patients with type 2 diabetes treated with oral antidiabetes $\operatorname{drug}(\mathrm{s})$ : results from a 26-week, randomized, open-label, parallel-group, multicenter, noninferiority study. Clin Ther. 2012;34(9):1892-1908.

66. Blevins T, Pullman J, Malloy J, et al. DURATION-5: exenatide once weekly resulted in greater improvements in glycemic control compared with exenatide twice daily in patients with type 2 diabetes. $J$ Clin Endocrinol Metab. 2011;96(5):1301-1310.

67. Diamant M, Van Gaal L, Stranks S, et al. Once weekly exenatide compared with insulin glargine titrated to target in patients with type 2 diabetes (DURATION-3): an open-label randomised trial. Lancet. 2010; 375(9733):2234-2243.

68. Buse JB, Drucker DJ, Taylor KL, et al. DURATION-1: exenatide once weekly produces sustained glycemic control and weight loss over 52 weeks. Diabetes Care. 2010;33(6):1255-1261.

69. Meloni AR, DeYoung MB, Han J, Best JH, Grimm M. Treatment of patients with type 2 diabetes with exenatide once weekly versus oral glucose-lowering medications or insulin glargine: achievement of glycemic and cardiovascular goals. Cardiovasc Diabetol. 2013;12:48.

70. Diamant M, Van Gaal L, Stranks S, et al. Safety and efficacy of onceweekly exenatide compared with insulin glargine titrated to target in patients with type 2 diabetes over 84 weeks. Diabetes Care. 2012;35(4): 683-689.

71. Drucker DJ, Buse JB, Taylor K, et al. Exenatide once weekly versus twice daily for the treatment of type 2 diabetes: a randomised, openlabel, non-inferiority study. Lancet. 2008;372(9645):1240-1250.

72. Onishi Y,KoshiyamaH,Imaoka T,HaberH,Scism-BaconJ,BoardmanMK. Safety of exenatide once weekly for 52 weeks in Japanese patients with type 2 diabetes mellitus. J Diabetes Invest. 2013;4(2):182-189.

73. Buse JB, Nauck M, Forst T, et al. Exenatide once weekly versus liraglutide once daily in patients with type 2 diabetes (DURATION-6): a randomised, open-label study. Lancet. 2013;381(9861):117-124.

74. Buse JB, Rosenstock J, Sesti G, et al. Liraglutide once a day versus exenatide twice a day for type 2 diabetes: a 26-week randomised, parallel-group, multinational, open-label trial (LEAD-6). Lancet. 2009; 374(9683):39-47.

75. Nauck M, Frid A, Hermansen K, et al. Efficacy and safety comparison of liraglutide, glimepiride, and placebo, all in combination with metformin, in type 2 diabetes: the LEAD (liraglutide effect and action in diabetes)-2 study. Diabetes Care. 2009;32(1):84-90.

76. Russell-Jones D, Vaag A, Schmitz O, et al. Liraglutide versus insulin glargine and placebo in combination with metformin and sulfonylurea therapy in type 2 diabetes mellitus (LEAD-5 met+SU): a randomised controlled trial. Diabetologia. 2009;52(10):2046-2055.

77. Marre M, Shaw J, Brändle M, et al. Liraglutide, a once-daily human GLP-1 analogue, added to a sulphonylurea over 26 weeks produces greater improvements in glycaemic and weight control compared with adding rosiglitazone or placebo in subjects with type 2 diabetes (LEAD-1 SU). Diabetic Med. 2009;26(3):268-278.

78. Syed YY, McCormack PL. Exenatide Extended-Release: An Updated Review of Its Use in Type 2 Diabetes Mellitus. Drugs. 2015;75(10): $1141-1152$

79. Wysham C, Grimm M, Chen S. Once weekly exenatide: efficacy, tolerability and place in therapy. Diabetes Obes Metab. 2013;15(10): $871-881$.

80. Fineman MS, Shen LZ, Taylor K, Kim DD, Baron AD. Effectiveness of progressive dose-escalation of exenatide (exendin-4) in reducing dose-limiting side effects in subjects with type 2 diabetes. Diabetes Metab Res Rev. 2004;20(5):411-417. 
81. Giovannucci E, Harlan DM, Archer MC, et al. Diabetes and cancer: a consensus report. Diabetes Care. 2010;33(7):1674-1685.

82. Guillermin A, Lloyd A, Best JH, DeYoung MB, Samyshkin Y, Gaebler JA. Long-term cost-consequence analysis of exenatide once weekly versus sitagliptin or pioglitazone for the treatment of type 2 diabetes patients in the United States. J Med Econ. 2012;15(4):654-663.

83. Beaudet A, Palmer JL, Timlin L, et al. Cost-utility of exenatide once weekly compared with insulin glargine in patients with type 2 diabetes in the UK. J Med Econ. 2011;14(3):357-366.

84. Samyshkin Y, Guillermin AL, Best JH, Brunell SC, Lloyd A. Long-term cost-utility analysis of exenatide once weekly versus insulin glargine for the treatment of type 2 diabetes patients in the US. J Med Econ. 2012; 15 Suppl 2:6-13.
85. Gaebler JA, Soto-Campos G, Alperin P, et al. Health and economic outcomes for exenatide once weekly, insulin, and pioglitazone therapies in the treatment of type 2 diabetes: a simulation analysis. Vasc Health Risk Manag. 2012;8:255-264.

86. Wang B, Roth JA, Nguyen H, Felber E, Furnback W, Garrison LP. The short-term cost-effectiveness of once-daily liraglutide versus once-weekly exenatide for the treatment of type 2 diabetes mellitus in the United States. PLoS One. 2015;10(4):e0121915.

87. Kim D, MacConell L, Zhuang D, et al. Effects of once-weekly dosing of a long-acting release formulation of exenatide on glucose control and body weight in subjects with type 2 diabetes. Diabetes Care. 2007;30(6): $1487-1493$.

\section{Publish your work in this journal}

Therapeutics and Clinical Risk Management is an international, peerreviewed journal of clinical therapeutics and risk management, focusing on concise rapid reporting of clinical studies in all therapeutic areas, outcomes, safety, and programs for the effective, safe, and sustained use of medicines. This journal is indexed on PubMed Central, CAS,
EMBase, Scopus and the Elsevier Bibliographic databases. The manuscript management system is completely online and includes a very quick and fair peer-review system, which is all easy to use. Visit $\mathrm{http}: / / \mathrm{www}$.dovepress.com/testimonials.php to read real quotes from published authors. 